\title{
PERANCANGAN DAN PENERAPAN E-MARKETPLACE UNTUK USAHA KECIL DAN MENENGAH PADA LEMBAGA PEMBERDAYAAN MASYARAKAT KELURAHAN DEPOK JAYA
}

\author{
Dede Hendra, Ani Merati, Siti Aprilliani, Muhamad Faozan Afandi, Nardiono \\ Program Studi Manajemen \\ Universitas Pamulang \\ Email: dosen02272@unpam.ac.id
}

\begin{abstract}
This community service activity aims to socialize and provide counseling related to knowledge on how to maximize sales through online marketing by opening a business in E-Marketplac. The method used in the form of delivery of material in the form of presentation theory and practice / application of account creation in the E-Marketplace. The method of activity used is in collaboration with the Community Empowerment Institute (LPM) of Depok Village, the activity is carried out at Al Awwal Mosque Jalan Mawar Raya Depok Jaya and provides solutions in accordance with the problems faced by providing training in the form of materials and practices aimed at developing the ability to increase marketing via online media in the E-Marketplace for participants from $L P M$. The results of the activity showed that prior to the implementation of the PKM, participants from the Community Empowerment Institute (LPM) had known several types of E-Marketplaces, which were related to marketing products through online media that were in one Market, but they only knew the types of E-Marketplaces. of course, they have not been able to create an account and publish products into the E-Marketplace account. However, after the implementation of the activity it was known that the participants from the LPM could understand the basics of creating an account by choosing a Marketplace that was in accordance with the products / services they would market in order to achieve the right target.
\end{abstract}

Keywords: E-Marketplace, Small and Medium Enterprises

\begin{abstract}
Abstrak
Kegiatan pegabdian kepada masyarakat ini bertujuan untuk mensosialisasikan dan memberikan penyuluhan terkait pengetahuan bagaimana cara memaksimalkan penjualan melalui pemasaran online yaitu dengan membuka usaha di E-Marketplac. Adapun metode yang dilakukan berupa penyampian materi dalam bentuk teori presentasi dan
\end{abstract}


praktik/penerapan pembuatan akun di E-Marketplace. Metode kegiatan yang digunakan adalah bekerjasama dengan Lembaga Pemberdayaan Masyarakat (LPM) Kelurahan Depok, kegiatan dilaksanakan di Masjid Al Awwal Jalan Mawar Raya Depok Jaya dan memberikan solusi sesuai dengan permasalahan yang dihadapi yaitu memberikan pelatihan dalam bentuk materi dan praktek yang bertujuan mengembangkan kemampuan untuk meningkatkan pemasaran via media online di E-Marketplace bagi para peserta dari LPM. Hasil kegiatan menunjukkan bahwa sebelum pelaksanaan PKM, para peserta dari Lembaga Pemberdayaan Maasyarakat (LPM) sudah mengenal beberapa jenis E-Marketplace, yang terkait dengan pemasaran produk lewat media online yang berada didalam satu Market, tetapi mereka hanya mengetahui jenis-jenis E-Marketplace nya saja, mereka belum bisa membuat akun dan melakukan publikasi produk ke dalam akun E-Marketplace tersebut. Namun setelah pelaksaan kegiatan diketahui para peserta dari LPM tersebut dapat memahami dasar-dasar pembuatan akun dengan cara memilih Marketplace yang sesuai dengan produk/jasa yang akan mereka pasarkan agar dapat mencapai sasaran yang tepat.

Kata kunci : E-Marketplace, Usaha Kecil dan Menengah

\section{A. PENDAHULUAN}

Sistem Informasi adalah suatu kegiatan dari prosedur-prosedur yang diorganisasi, bilamana dieksekusi akan menyediakan informasi untuk mendukung pengambil keputusan dan pengendalian di dalam organisasi. Berdasarkan beberapa pengertian sistem informasi menurut para ahli tersebut dapat disimpulkan Sistem Informasi merupakan suatu kombinasi yang teratur yang terdiri dari komponen-komponen yang dibuat oleh manusia yang bila eksekusi akan menyediakan informasi untuk mendukung pengambilan keputusan. Indonesia merupakan pasar dengan pertumbuhan e-commerce yang menarik dari tahun ke tahun. Sejak tahun 2014, Euromonitor mencatat, penjualan online di Indonesia sudah mencapai US $\$ 1,1$ miliar. Data sensus Badan Pusat Statistik (BPS) juga menyebut, industri e-commerce Indonesia dalam 10 tahun terakhir meningkat hingga 17 persen dengan total jumlah usaha ecommerce mencapai 26,2 juta unit. Pada tahun 2018, e-commerce di Indonesia tercatat mengalami pertumbuhan sangat pesat, dan diperkirakan akan terus meningkat seiring berkembangnya jumlah pengusaha dan pelaku Usaha Mikro Kecil dan Menengah (UMKM) di tanah air. Di samping data tersebut, potensi besar industri e-commerce di Indonesia juga dipengaruhi oleh gaya belanja online, terutama oleh generasi milenial.

Menurut Indonesia Millennial Report 2019, milenial sangat suka mencari perbandingan harga, fitur, program promo dan kualitas produk di beberapa e-commerce sebelum memutuskan membeli sebuah barang. Para milenial juga tidak segan untuk merekomendasikan e-commerce atau toko online favorit mereka kepada teman-teman mereka. Selama kurun waktu 4 tahun terakhir, e-commerce di Indonesia mengalami peningkatan hingga 500 persen. Riset terbaru Google dan Temasuk dalam laporan e-Conomy 
SEA 2018 menunjukkan bahwa ekonomi digital Indonesia tahun ini mencapai US\$27 miliar atau sekitar Rp391 triliun. Angka tersebut menjadikan transaksi ekonomi digital Indonesia berada di peringkat pertama untuk kawasan Asia Tenggara dengan kontribusi sebesar 49 persen. Meski demikian, produk-produk asal Indonesia yang dijual di platform e-commerce masih di bawah 10 persen sehingga menjadi tantangan bersama agar membuat digital ekonomi dan e-commerce tidak hanya besar karena Indonesia sebatas sebagai market saja. Perkembangan teknologi informasi dan komunikasi dewasa ini berlangsung dengan sangat pesat. Hal ini tidak terlepas dari keberadaan internet sebagai salah satu media komunikasi dan penyedia informasi. Dengan adanya internet seseorang dapat menyampaikan informasi ke mana saja dan kepada siapa saja. Tanpa dibatasi oleh tempat ruang, maupun waktu tertentu termasuk dalam dunia usaha.

Dalam dunia bisnis peranan internet telah dirasakan semakin penting dan berarti, karena melalui internet pula para pelaku usaha dapat melakukan transaksi bisnisnya secara online di mana pun berada. Tanpa internet, para pelaku bisnis yang terpisah oleh jarak dan waktu dapat dipastikan akan mengalami masalah dan kesulitan dalam hal waktu dan biaya didalam melakukan transaksi bisnis serta memperluas jaringan bisnisnya. Saat ini para pelaku bisnis pada umumnya masih melakukan transaksi bisnisnya secara manual melalui tatap muka secara langsung ataupun melalui telepon, seperti halnya yang dilakukan oleh masyarakat kelurahan Depok Jaya, dari hal tersebut terkadang muncul permasalahan seperti janji untuk pertemuan yang tidak bisa ditepati ataupun tidak ada di tempat pada saat dihubungi atau tuntutan yang mengharuskan mereka keluar secara aktif dalam memperluas jaringan penawaran produknya kepada customer yang ada. Untuk itu, kami Dosen Universitas Pamulang dan mahasiswa akan mengadakan Pengabdian Kepada Masyarakat (PKM) bekerjasama dengan Lembaga Pemberdayaan Masyarakat (LPM) Kelurahan Depok Jaya untuk memberikan pelatihan kepada Ketua Rukun Warga di Kelurahan Depok Jaya dengan judul " Perancangan dan Penerapan E-Markeplace Pada Usaha Kecil dan Menengah". Adapun lokasi Kelurahan depok jaya berapa di Sebelah Utara berbatasan dengan Kelurahan Beji Kecamatan Beji Sebelah Timur berbatasan dengan Kelurahan Depok, Kecamatan Pancoran Mas Sebelah Selatan berbatasan dengan Kelurahan Pancoran Mas, Kecamatan Pancoran Mas Sebelah Barat berbatasan dengan Kel. Pancoran Mas Kec. Pancoran Mas dan Tanah Baru, Kec. Beji Luas Wilayah : 113 ha Terdiri dari 14 Rukun Warga (RW) dan 108 Rukun Tetangga (RT) Jumlah Penduduk : Berdasarkan registrasi kependudukan pada Kelurahan Depok Jaya, jumlah laki-laki 14.988 jiwa, perempuan 15.558 jiwa, jumlah seluruhnya 30.546 jiwa.

\section{B. METODE PELAKSANAAN KEGIATAN}

Untuk menghadapi permasalahan di atas dengan menggunakan berbagai metode, diantaranya Metode dalam kegiatan ini merupakan pemberian teori dan langkah-langkah membangun usaha di EMarkeplace, dengan melalui beberapa tahapan, adapun tahapannya yaitu:

Tahap persiapan, tahapan ini dilakukan terlebih dahulu seperti pemantapan dan penentuan lokasi dan sasaran, dalam tahapan ini meliputi Tahap Survey Awal yaitu pada tahap ini dilakukan peninjauan dan survey langsung di lapangan untuk memperoleh dan mengumpulkan informasi yang dibutuhkan. Dari hasil tahapan ini, proses pemasaran dan jual 
beli masih dilakukan secaara manual seperti off store dan pembukuaanya juga diproses secara manual.

Tahap pemberian teori, tahap ini akan menjelaskan terkait keuntungan dan kelebihan proses usaha menggunakan E-Marketplace, teori ini di dapat dari pengalaman sendiri dan studi literatur yaitu dengan mencari teori dari berbagai sumber yang berhubungan dengan EMarketplace.

Tahap melihat pasar, tahap ini memiliki tujuan untuk menyiapkan produk yang akan dijual sehingga akan disesuaikan dengan nama toko, disamping itu juga bertujuan untuk memberikan rekomendasi produk yang memiliki potensi nilai jual tinggi di pasar.

Tahap perancangan usaha, tahap ini dilakukan setelah persiapan produk dan peralatan lengkap serta penentuan E-Marketplacenya. Tahap ini juga dilaksanakan setelah semua peserta memiliki produk yang akan di jual, sehingga akan mempermudah pada proses tahap selanjutnya, dengan kata lain pada tahapan ini adalah memilih marketplace yang baik. Pada tahapan ini juga, dilakukan pilihan akan kebutuhan sistem, maka secara otomatis telah melakukan sistem yang baik, yang akan digunakan dalam perancangan dan pembangunan sistem e-commerce.

Proses tanya jawab, tahap ini bertujuan apabila ada hal yang harus di diskusikan terlebihdahulu sebelum implementasinya, tahap ini juga berlangsung saat proses implementasi berlangsung, permasalah pada masing-masing E-Marketplace juga tidak sama, sehingga perlu analisa lebih misal permasalahan di Lazada akan berbeda dengan permasalahan yang ada di shopee, berikut dengan Marketplace lainnya.

Tahap penerapan usaha, tahapan ini adalah implementasi dari teori dan sekaligus pembuatan toko di E-Markeplacenya. Dengan tahapan terakhir ini diharapkan semua peserta yang sudah memiliki produk dan tidak (khusus untuk yang jadi dropshiper) akan mengimplementasikan semua tahapan diatas, sehingga akan di sesuaikan dengan masingmasing unit usaha atau produk yang dimiliki. Dari semua tahapan-tahapan diatas juga, semua marketplace tidak sama sehingga penentuan pemilihan marketplace mempengaruhi tahapan selanjutnya. Disamping itu, melakukan deteksi masalah terhadap sistem usaha yang masih dilakukan secara manual yaitu dengan melakukan perumusan-perumusan masalah apa saja yang dapat menjadi kendala pada sistem usaha ini, sehingga dapat diketahui permasalahannya. Setelah dilakukan deteksi masalah yang ada tersebut maka mulailah dilakukan tahapan yang sesuai dengan masalah yang terjadi. Kegiatan ini bekerjasama dengan Lembaga Pemberdayaan Masyarakat Kelurahan Depok Jaya di Masjid Al Awwal Jalan Mawar Raya Depok Jaya dan mencari pemasalahan yang ada di tempat tersebut sehingga dapat memberikan solusi yang tepat dalam mengatasi garis kemiskinan di Depok Jawa Barat khususnya Kelurahan Depok Jaya. Setelah di analisis maka kami memberikan pelatihan dalam bentuk materi dan praktek dalam Perancangan dan Penerapan E-Marketplace Untuk Usaha Kecil dan Menengah di Kelurahan Depok Jaya. Adapun jadwal pengabdian masyarakat yang sudah disepakati antara Tim PKM Universitas Pamulang dengan LPM Kelurahan Depok Jaya yaitu pada tanggal 27 s.d 29 Oktober 2019 di LPM Kelurahan Depok Jaya. 


\section{HASIL DAN PEMBAHASAN}

Menurut Teguh Wahyono (2004:17), Sistem Informasi merupakan suatu sistem yang dibuat oleh manusia yang terdiri dari komponen-komponen dalam organisasi untuk mencapai suatu tujuan yaitu menyajikan informasi. Menurut O'Brien (2005:5), Sistem Informasi adalah suatu kombinasi teratur apapun dari orang, perangkat keras, piranti lunak, jaringan komunikasi, dan basis data yang mengumpulkan, mengubah dan menyebarkan inforamsi di dalam suatu bentuk organisasi. Menurut Henry C. Lucas dalam jogiyanto (2000:35), Sistem Informasi adalah suatu kegiatan dari prosedur-prosedur yang diorganisasi, bilamana dieksekusi akan menyediakan informasi untuk mendukung pengambil keputusan dan pengendalian di dalam organisasi.

Berdasarkan beberapa pengertian sistem informasi menurut para ahli tersebut dapat disimpulkan sistem informasi merupakan suatu kombinasi yang teratur yang terdiri dari komponen-komponen yang dibuat oleh manusia yang bila eksekusi akan menyediakan informasi untuk mendukung pengambilan keputusan. Mengenai hal tersebut ada sistem yang sering digunakan dalam dunia usaha untuk menjual barang dan hasil produksinya yaitu disebut E-Marketplace.

E-Marketplace adalah salah satu layanan e-commerce yang menjadi tempat bertemunya antara penjual dan pembeli secara online untuk melakukan proses transaksi jual beli. Selama ini proses jual beli di beberapa marketplace di Indonesia tidak dikelola langsung oleh pihak marketplace sehingga mengakibatkan besarnya peluang transaksi menjadi tidak aman. Kelemahan lainnya sistem tidak dapat menangani pengembalian uang jika ternyata penjual tidak mengirimkan barang yang dipesan oleh pembeli.

Di Indonesia saat ini, E-marketplace sudah banyak bermunculan, walalupun kebanyakan bentuk yang dianut E-marketplace di Indonesia pada saat ini adalah berbentuk advertising atau iklan. Dimana interaksi langsung terjadi antara buyer dan seller, sedangkan penyedia E-marketplace hanya berfungsi menyediakan tempat saja. Penyedia jasa Emarketplace, tidak lagi tahu menahu transaksi yang dilakukan oleh buyer dan seller.

Bentuk E-marketplace lainnya adalah auction atau lelang, dimana pada bentuk ini Emarketplaceberfungsi sebagai auction ground. Seller akan memajang barang yang ditawarkan beserta harga awal, lalu buyer's akan mengajukan penawaran. Setelah jangka waktu tertentu, seller akan memilih tawaran terbaik, dan buyer yang mengajukan penawaran tersebut berhak mendapatkan barang yang dijual oleh seller.

Bentuk E-marketplace seperti yang telah disebutkan diatas memiliki kekurangan, antara lain adalah masih bersifat "Satu transaksi pembelian dalam satu waktu ". Hal ini terjadi karena, pada saat buyer membeli barang dari satu seller, maka buyer akan berinteraksi langsung dengan seller tersebut, hal ini akan merepotkan buyer, pada saat ia akan membeli barang dari beberapa seller sekaligus. Keamanan transaksi juga kurang, karena proses transaksi langsung. Melibatkan buyer dan seller tanpa adanya perantara pihak ke tiga, maka tidak ada jaminan buyer aman dari penipuan pihak-pihak tidak bertanggung jawab. Sementara bagi seller, masalah yang timbul adalah pada saat mengelola permintaan dari buyer, ada kalanya timbul beberapa masalah, mulai dari data pesanan/pemesan yang kurang jelas, ketidaktersediaan barang, tidak adanya history penjualan, hingga masalah kepercayaan buyer terhadap seller. 
E-Marketplace juga bisa menjadi solusi untuk mengatasi permasalahan yang di uraikan dalam pendahuluan maka dirancanglah suatu aplikasi E-marketplace, yang diharapkan dapat menjadi tempat bagi customer maupun supplier dalam memasarkan dan mencari produk yang dibutuhkan. E-marketplace ditujukan untuk menjadi tempat pertemuan antara pihak suppliercustomer baik dalam memasarkan maupun mencari produk yang dibutuhkan. Penggunaan teknologi atau E-Marketplace ini diharapkan dapat memberikan manfaat yang besar terhadap para pelaku usaha atau bisnis yang kompetitif, para pelaku yang dapat bersaing dalam kompetisi adalah para pelaku usaha yang mampu mengimplementasikan teknologi dalam usahanya. Salah satu jenis implementasi dalam hal meningkatkan persaingan bisnis adalah degnan menggunakan electric commerce (e-commerce) yaitu untuk memasarkan berbagai macam produk atau jasa, baik dalam bentuk fisik maupun digital. Dengan ini e-commerce didefinisikan sebagai proses pembelian dan penjualan antara dua belah pihak di dalam suatu perusahaan dengan adanya pertukaran barang, jasa atau informasi melalui media internet (Indrajit, 2001).

Hasil kegiatan ini menunjukkan bahwa sebelum pelaksanaan Pengabdian Kepada Masyarakat (PKM), para peserta dari Lembaga Pemberdayaan Maasyarakat (LPM) sudah mengenal beberapa jenis E-Marketplace, yang terkait dengan pemasaran produk lewat media online yang berada didalam satu Market, akan tetapi mereka hanya mengetahui jenis-jenis EMarketplace nya saja, mereka belum bisa membuat akun dan melakukan publikasi produk ke dalam akun E-Marketplace tersebut, disamping itu juga para peserta tidak mengetahui potensi berjualan produk secara online tersebut. Namun setelah pelaksaan kegiatan diketahui para peserta dari LPM dapat memahami dasar-dasar pembuatan akun dengan cara memilih Marketplace yang sesuai dengan produk atau jasa yang akan mereka pasarkan agar dapat mencapai sasaran yang tepat sehingga bisa memaksimalkan keuntungan dari usaha tersebut.

\section{KESIMPULAN DAN SARAN}

Pelaksanaan kegiatan Pengabdian Kepada Masyarakat oleh Lembaga Penelitian dan Pengabdian Masyarakat (LPPM) Universitas Pamulang yang dilakukan oleh dosen-dosen program studi Manajemen telah berjalan dengan lancar dan mendapat sambutan hangat dari tempat pelaksanaan kegiatan ini yaitu Kepala Formu Muslimah Depok. Harapan kami dengan pengabdian ini dapat menambah ilmu yang bermanfaat dalam penyuluhan Perancangan dan Penerapan E-Marketplace untuk Usaha Kecil dan Menengah. Dalam laporan kegiatan ini mungkin banyak kekurangan yang ada, untuk itu kami berharap masukan dan kritikan dalam rangka perbaikan untuk kegiatan-kegiatan pengabdian masyarakat di masa yang akan datang. Semoga kegiatan pengabdian masyarakat ini dapat bermanfaat bagi masyarakat sekitar lingkungan Universitas Pamulang dan lainnya. Akhirnya, kami mengucapkan terima kasih kepada seluruh pihak yang telah mendukung kegiatan yang kami laksanakan dan kami mohon maaf apabila dalam pelaksanaan dan tulisan ini banyak ditemukan kekurangan.

\section{DAFTAR PUSTAKA}

Indrajit, R. (2001). E-Commerce Kiat dan Strategi di Dunia Maya. Jakarta: PT Elex Media Komputerindo. 
Iyas, (2011) Implementasi Sistem Penjualan Online Berbasis E-Commerce Pada Usaha Rumah Griya Unik Wanita, UIN Syarif Hidayatullah Jakarta.

Solihin, D. (2020), Faktor-Faktor Yang Mempengaruhi Kinerja Pemasaran Pada PT Prima Ufuk Semesta (Studi Empiris Pada Outlet Rekanan PT. Prima Ufuk Semesta Di Wilayah Jabodetabek), Jurnal Semarak, Vol. 3. No. 1.

Solihin, D. (2020), Pengaruh Kualitas Pelayanan, Harga, Dan Promosi Terhadap Keputusan Pelanggan Dalam Memilih Klub Basket Satria Indonesia Tangerang Selatan, Jurnal Pemasaran Kompetitif, Vol. 3, No. 3.

STMIK MDP, Aplikasi E-Marketplace Berbasis Web 2.0

https://www.wartaekonomi.co.id/read216302/pertumbuhan-e-commerce-pesat-diindonesia.html

https://panmas.depok.go.id/profil/kelurahan/kelurahan-depok-jaya 